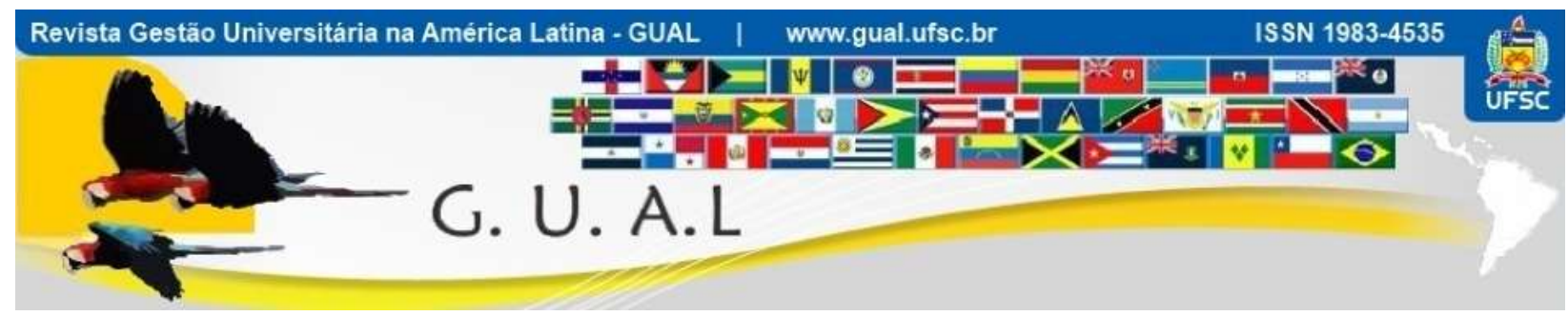

DOI: http://dx.doi.org/10.5007/1983-4535.2020v13n2p92

\title{
EDUCAÇÃO PARA A SUSTENTABILIDADE NA GESTÃO ESTRATÉGICA DE UNIVERSIDADES COMUNITÁRIAS
}

\section{EDUCATION FOR SUSTAINABILITY IN THE STRATEGIC MANAGEMENT OF COMMUNITY UNIVERSITIES}

Suelen Geíse Telocken, Mestre
https://orcid.org/0000-0001-5500-9561
stelocken@gmail.com

Recebido em 26/outubro/2019

Aprovado em 06/março/2020

Publicado em 01/maio/2020

Sistema de Avaliação: Double Blind Review 


\title{
RESUMO
}

A sustentabilidade está presente na universidade dentro dos diferentes sistemas que lá coexistem, sendo cada vez mais levados em consideração para as ações de ensino, pesquisa, extensão e gestão universitária. Logo, é de extrema importância pesquisar o modo pelo qual a sustentabilidade exerce influência na gestão das universidades e em seus setores pedagógicos. Principalmente quando se trata de universidade públicas não estatais, que é o caso das universidades comunitárias. O objetivo desta pesquisa é evidenciar os elementos que permitem a integração da temática sustentabilidade sob a perspectiva das dimensões contextual, organizacional, curricular e pedagógica em universidades comunitárias por meio da gestão estratégica. Para tal, aplicou-se, questionários e entrevistas com os gestores das universidades comunitárias. A partir disso, procurou-se evidenciar os elementos que permitem a integração da temática sustentabilidade sob a perspectiva das dimensões contextual, organizacional, curricular e pedagógica em universidades comunitárias por meio da gestão estratégica, destacando-se como facilitador da inserção da temática o caráter comunitário dessas universidades. Por fim, foi possível apresentar possibilidades de avanços para a integração da sustentabilidade em universidades comunitárias a partir da gestão estratégica, principalmente no que tange o protagonismo do Comung quanto a ações sobre a temática.

Palavras-chave: Administração. Desenvolvimento Sustentável. Instituições de Ensino Superior.

\begin{abstract}
Sustainability is present in the university within the different systems that coexist there, being increasingly taken into account for teaching, research, extension and university management actions. Therefore, it is extremely important to research the way in which sustainability exerts influence in the management of universities and in their pedagogical sectors. Particularly when it comes to non-state public university, which is the case of community universities. The objective of this research is to highlight the elements that allow the integration of the sustainability theme from the perspective of contextual, organizational, curricular and pedagogical dimensions in community universities through strategic management. To this end, questionnaires and interviews with the managers of the community universities were applied. From this, it was tried to evidence the elements that allow the integration of the sustainability theme from the perspective of the contextual, organizational, curricular and pedagogical dimensions in community universities through strategic management, emphasizing as facilitator of the insertion of the theme the community character of these universities. Finally, it was possible to present possibilities of advancement for the integration of sustainability in community universities from the strategic management, especially as far as Comung's role in actions on the theme is concerned.
\end{abstract}

Keywords: Administration. Sustainable Development. Higher Education Institutions. 


\section{EDUCAÇÃO PARA A SUSTENTABILIDADE NA GESTÃO ESTRATÉGICA DE UNIVERSIDADES

\section{INTRODUÇÃO}

Um período de expansão tecnológica e científica amplo apresenta-se no século atual, com descobertas geniais, mas com o legado de um desequilíbrio ambiental que ameaça a continuidade da vida dos seres humanos no planeta Terra. Percebe-se que o desenvolvimento econômico-social trouxe, além de benefícios, a degradação ambiental e a sequela de um subdesenvolvimento de várias nações. Em resposta à crise ambiental, a sociedade deve buscar o envolvimento de todos os setores que a compõe, além de iniciar uma nova relação entre o homem e o meio ambiente que o cerca (CALGARO, 2016).

Nesse sentido, Lauder et al (2006) apontam que a educação é uma ferramenta importante para a preparação de indivíduos para uma sociedade sustentável. Segundo Hesselink, Kempen e Wals (2000), a perspectiva educacional traz as noções de aprendizagem individual, pedagogia e emancipação. Os autores complementam seu posicionamento com uma pesquisa realizada com diversos professores a qual mostra que a Educação para a Sustentabilidade é considerada uma força, fenômeno ou ferramenta dentro da educação contemporânea, tanto formal e não-formal, e que possui valor agregado para tratar questões relacionadas ao meio ambiente e à sociedade. Dado esse contexto, o presente trabalho pretende evidenciar os elementos que permitem a integração da temática sustentabilidade sob a perspectiva das dimensões contextual, organizacional, curricular e pedagógica em universidades comunitárias por meio da gestão estratégica. O problema de pesquisa a ser investigado é quais os elementos que permitem a integração da temática sustentabilidade em universidades comunitárias sob a perspectiva das dimensões contextual, organizacional, curricular e pedagógica por meio da gestão estratégica?

Evidencia-se em estudos que a sustentabilidade em universidades, muitas vezes, parte de iniciativas particulares, motivadas por professores ou interessados no assunto ficando restrito a estas pessoas e seu grupo de aproximação (THOMAS; HERGARTY; HOLDSWORTH, 2012; MARQUES, 2016). Este é mais um motivo para ter-se a sustentabilidade estruturada em um modelo a partir da gestão estratégica, a fim de disseminar a sustentabilidade transversalmente em toda a universidade. Não como coerção ou imposição, mas sim que a gestão estratégica revele possiblidades de aproximação em cada área, de forma gradual para que, com o tempo, o assunto faça parte, naturalmente, das disciplinas (FIGUEIRÓ, 2015). 


\section{REFERENCIAL TEÓRICO}

Este capítulo é composto por um apanhado teórico-conceitual que abrange os principais aspectos relevantes para esta pesquisa sobre os temas: gestão estratégica em universidades e a educação para a sustentabilidade, a fim de melhor evidenciar os elementos que permitem a integração da temática sustentabilidade sob a perspectiva das dimensões contextual, organizacional, curricular e pedagógica em universidades comunitárias por meio da gestão estratégica.

\subsection{GESTÃO ESTRATÉGICA}

Hafsi e Martinet (2008) defendem que a gestão estratégica é claramente a arte de guiar a ação, e de fornecer subsídios, conceitos e métodos provados que permitam conceber melhor e usar as vias e meios mais adequados para a organização em função dos seus contextos específicos. Para Leite (2014), a administração estratégica está inserida em um processo que possui determinada etapas teóricas. Entre as principais etapas podemos destacar: execução de uma análise do ambiente, estabelecimento de uma diretriz organizacional, formulação de uma estratégia organizacional, implementação da estratégia. Todas essas etapas definem o resultado final da organização, o que evidencia que se a sustentabilidade fizer parte desse processo poderá gerar resultados não só na organização mas também no contexto em que ela está inserida.

Segundo Meyer Jr. (2005), a gestão estratégica de universidades tem sido desafiada em sua capacidade de responder às demandas externas, como forma indispensável de sobreviver, no curto prazo, e de garantir sua sobrevivência, no longo prazo. Isso tem feito com que essas instituições se lancem à busca de um gerenciamento estratégico que lhes permita melhor definição de objetivos, estabelecimento de prioridades, uso mais adequado dos recursos e, em especial, materialização das estratégias. Assim, em um estudo mais recente Meyer et al (2012), destaca que um dos aspectos críticos da gestão universitária tem sido a prática de estratégias que permitam a esse tipo de organização alcançar o desempenho desejado e se manter competitiva no setor.

A gestão estratégica praticada em universidades brasileiras tem sido associada, em geral, à chegada de um novo reitor ou de uma nova administração (pró-reitorias), e sua prática está quase sempre associada à elaboração de um plano estratégico. Esse plano, por sua vez, refere-se a um documento formal, de caráter político e institucional, que serve de referência e 
justificativa para as principais ações organizacionais, além de cumprir o papel de legitimar as intenções da nova administração perante a comunidade acadêmica (MEYER JR. PASCUCCI E MANGOLIN, 2012).

\subsection{EDUCAÇÃO PARA A SUSTENTABILIDADE}

Os desafios para alcançar a sustentabilidade são diversos. Não obstante, a Agenda 21, criada na II Conferência das Nações Unidas para o Meio Ambiente e o Desenvolvimento, ocorrida no Rio de Janeiro, Brasil, em 1992, conhecida como RIO-92, preconizava o papel central da educação na evolução do desenvolvimento sustentável. A frequência da utilização dos termos "educação", "sensibilização do público" e "formação", no âmbito da Agenda 21, colocou a educação como um dos principais meios para alcançar a sustentabilidade (TILBURY e WORTMAN, 2004). A partir disso as instituições de ensino superior, vem encontrando apoio, em nível nacional, para fortalecer uma formação pró-sustentabilidade. (TILBURY E WORTMAN, 2008)

A educação para a sustentabilidade aponta para propostas pedagógicas centradas na criticidade dos sujeitos, com vistas à mudança de comportamento e atitudes, ao desenvolvimento da organização social e da participação coletiva. Essa mudança paradigmática implica uma mudança de percepção e valores, gerando um pensamento complexo, aberto às indeterminações, às mudanças, à diversidade, à possibilidade de construir e reconstruir, em um processo contínuo de novas leituras e interpretações, configurando novas possibilidades de ação (JACOB et al 2011).

Como já exposto na introdução, a Organização das Nações Unidas para Educação, Ciência e Cultura (UNESCO), criou, em 2005, a DEDS. Esse documento possui em sua essência uma ideia simples, entretanto com implicações complexas; exalta a educação como o único modo de se alcançar a sustentabilidade. Conforme exposto abaixo:

- A educação deve inspirar a crença que cada um de nós tem o poder e a responsabilidade de introduzir mudanças positivas em escala global.

-A educação é o principal agente de transformação para o desenvolvimento sustentável, aumentando a capacidade das pessoas de transformarem sua visão de sociedade em realidade.

-A educação incentiva os valores, o comportamento e os estilos de vida necessários para um futuro sustentável. 
-A educação para o desenvolvimento sustentável é um processo em que se aprende a tomar decisões que levem em consideração o futuro em longo prazo de igualdade, economia e ecologia de todas as comunidades.

-A educação fortalece a capacidade de reflexão orientada para o futuro. (UNESCO, 2005, p 44.)

A DEDS evidencia que é necessária uma revisita à política educacional, no sentido de reorientar a educação desde jardim de infância até a universidade e o aprendizado permanente na vida adulta, para que esteja claramente focada na aquisição de conhecimentos, competências, perspectivas e valores relacionados à sustentabilidade. Escolas e universidades não são apenas lugares para se aprender sobre desenvolvimento sustentável, mas lugares onde as crianças podem, ativamente, implementar boas práticas de desenvolvimento sustentável, por exemplo, na economia de energia, na reciclagem, no uso produtivo do terreno das escolas, e no uso de materiais e recursos naturais (UNESCO, 2005, P 60-61.).

Para uma inserção da sustentabilidade mais efetiva em universidades evidencia-se quatro diferentes dimensões operacionais que estão interligadas e são interdependentes no processo de mudança e adaptação das instituições de ensino, sendo elas: contextual, organizacional, curricular e pedagógica (KURUCZ, COLBERT E MARCUS 2013; FIGUEIRÓ, 2015.

Segundo Kurucz, Colbert e Marcus, (2013) a dimensão contextual leva em consideração a influência do governo, as restrições legais e as dinâmicas de mercado. No que se refere a dimensão organizacional, uma vez que a sustentabilidade está sendo introduzida aos poucos, há a reconstrução de valores e a criação de uma nova cultura universitária. A dimensão curricular aborda o currículo. A integração da sustentabilidade, por sua vez, exige novas propostas pedagógicas interdisciplinares, em que a visão integrada, sistêmica e holística substitua os projetos pedagógicos disciplinares que privilegiam o processo de compreensão do aluno sobre sua realidade de forma fragmentada (DEMAJOROVIC e SILVA, 2012, p.45). E por fim, a dimensão pedagógica aborda os métodos utilizados para a integração da sustentabilidade. Armstrong (2011) aponta que, para que a EpS seja internalizada pelo aluno com sucesso, as preferências pedagógicas devem ser orientadas para uma epistemologia construtivista, caracterizadas por altos níveis de envolvimento do aluno. 


\section{MÉTODO DE PESQUISA}

Quanto à abordagem, os procedimentos foram de natureza qualitativa, do tipo exploratório, adotando o estudo de caso com múltiplas unidades de análise como estratégia de pesquisa. Esse tipo de pesquisa visa à verificação e a transcrição das características de determinado cenário, sem a interferência do autor. Para Gil (1999), as pesquisas exploratórias buscam desenvolver conceitos e ideias para, assim, corroborar com estudos posteriores.

Primeiramente, foi aplicado questionário exploratório para 11 instituições Comunitárias de ensino do estado do Rio Grande do Sul, a coleta foi realizada no $5^{\circ}$ Fórum de Gestão e Inovação do Comung, realizado na data de 04 a 05/09/2017, que aconteceu no salão de atos da Universidade Feevale, Campus II, onde estavam presentes os representantes das gestões estratégicas das 11 universidades comunitárias, sendo elas: FEEVALE, PUCRS, UCPEL, UCS, UNICRIZ, UNIJUI, UNISC, UPF, URCAMP, URI e UNISINOS.

Após a aplicação dos questionários, buscou-se entrevistar os reitores das universidades comunitárias, adotou-se a proximidade geográfica, diferentes regiões de abrangência (ICES da região metropolitana e do interior do RS) e portes (número de alunos) como critérios de escolha das ICES pesquisadas, a fim de melhor evidenciar os elementos da temática desenvolvida pelo Consórcio e entender melhor a particularidade regional de cada universidade, e porte de cada instituição.

Destarte, seis universidades comunitárias, além da presidência do consórcio de instituições de ensino superior comunitárias do sul do Brasil, foram selecionadas para a pesquisa, sendo das seguintes regiões: Região da Campanha, Região Noroeste, Região Metropolitana e Capital, Região Norte e Região Sul, tendo assim uma visão ampla das universidades comunitárias do RS em relação à temática, uma vez que não haveria tempo hábil para realizar as entrevistas com todas as 11 universidade comunitárias, visto que a duração da presente pesquisa foi de apenas um ano. Para tanto, obteve-se retorno positivo de 4 instituições e da presidência do Consórcio (Quadro 1).

Logo, cinco entrevistas foram realizadas, entre janeiro e março de 2018, cada uma com duração que variou de uma hora a uma hora e 30 minutos. O roteiro utilizado e previamente elaborado nas entrevistas se baseou nos objetivos da pesquisa, na revisão da literatura e na adaptação final do modelo a parir da consulta a especialistas. O objetivo das entrevistas foi obter as percepções dos entrevistados quanto ao tema abordado (LAKATOS, 2011), e, entender o papel das gestões estratégicas universitárias a respeito da temática. 
Quadro 1 Universidades pesquisadas

\begin{tabular}{|c|c|c|c|}
\hline Instituição & Entrevistado(s) & Localização do(s) campus (i) & $\begin{array}{c}\text { Número de } \\
\text { alunos (base } \\
\text { 2014) }\end{array}$ \\
\hline $\begin{array}{c}\text { Consórcio de instituições de } \\
\text { ensino superior comunitárias do } \\
\text { sul do Brasil }\end{array}$ & $\begin{array}{c}\text { Presidente e Reitor } \\
\text { de uma universidade }\end{array}$ & Atuação em todo o RS & $\begin{array}{c}\text { Cerca de } 210 \\
\text { mil. }\end{array}$ \\
\hline Instituição A & $\begin{array}{c}\text { Pró-Reitor de } \\
\text { Administração }\end{array}$ & $\begin{array}{c}\text { Porto Alegre (campus } \\
\text { principal) e Viamão, na região } \\
\text { metropolitana de Porto Alegre. }\end{array}$ & Cerca de 30 mil. \\
\hline Instituição B & Reitora & $\begin{array}{c}\text { Situada no Vale do Rio dos } \\
\text { Sinos, a cerca de 45 } \\
\text { quilômetros da capital do } \\
\text { estado }\end{array}$ & Mais de 18 mil. \\
\hline Instituição C & Reitor & $\begin{array}{c}\text { Passo Fundo, no norte do RS e } \\
\text { cerca de 289 km de Porto } \\
\text { Alegre. }\end{array}$ & Mais de 12 mil. \\
\hline Instituição D & Reitora & $\begin{array}{c}\text { Cruz Alta, no noroeste do RS } \\
\text { e cerca de 350 km de Porto } \\
\text { Alegre. }\end{array}$ & Cerca de 4 mil. \\
\hline
\end{tabular}

Fonte: Elaborado pela autora.

Buscou-se documentação direta e indireta para esta pesquisa. Como fonte de documentação direta, a pesquisa se utilizou de roteiro semiestruturado com os reitores das universidades comunitárias, e entrevista com os reitores das universidades a fim de apresentar possibilidades de avanços para a integração da sustentabilidade em universidades comunitárias por meio da gestão estratégica.

O roteiro utilizado no questionário baseou-se no instrumento de pesquisa adaptado de Figueiró (2015), após sua reestruturação o instrumento foi validado por quatro especialista da área, sustentado nas dimensões operacionais: contextual, organizacional, curricular e pedagógica, para, dessa forma, evidenciar os elementos que permitem a integração da temática sustentabilidade sob a perspectiva das dimensões, por meio da gestão estratégica. Como forma de pesquisa indireta, utilizou-se de documentos internos, materiais de divulgação e dos sítios institucionais.

Logo, associando os questionários, a entrevista com reitores, a documentação indireta e as observações do pesquisador, buscou-se a melhor triangulação dos dados, para assim obter maior validade e confiabilidade na coleta dos dados nos diferentes momentos, com mais de um único instrumento (STAKE, 1998). Assim, os dados foram passados por constante comparação (STRAUSS; CORBIN, 1990), entre os resumos do pesquisador e os materiais impressos e digitais, visando avançar na discussão da EpS a partir da gestão estratégica. 
Finalizada a coleta dos dados, os mesmos foram tratados e compilados com o auxílio do software N-Vivo, versão 8. Utilizou-se a técnica de análise de conteúdo que tem por objetivo a compilação de mensagens para confirmar os indicadores que permitam inferir sobre outra realidade que não a da mensagem (BARDIN, 2011). Ressalta-se que os resultados desta pesquisa seguiram, rigorosamente, as etapas da análise de conteúdo segundo MORAES, 1999, para que não haja nenhum viés da autora neste caso categorias a priori. Segundo o mesmo autor a análise de conteúdo (AC) passa por três fases: pró-análise (fase de organização), exploração do material ("edição" das entrevistas transcritas, dos artigos recortados, das questões anotadas em fichas.) e tratamento dos resultados (o pesquisador procurara tornar os resultados significativos e válidos).

\section{ANÁLISE DOS RESULTADOS}

Este capítulo trata da análise e discussão da dos resultados com base nos objetivos do trabalho e na fundamentação teórico-conceitual. Para uma melhor visualização dos resultados, este capítulo está dividido nas 4 dimensões abrangidas neste estudo, sendo elas: contextual, organizacional, curricular e pedagógica. Em cada uma das quatro dimensões, os resultados foram triangulados entre questionários, entrevistas e pesquisa documental, além de observações da autora e na revisão da literatura, abrangendo aspectos gerais e específicos, ambos confirmados pela literatura.

\subsection{DIMENSÃO CONTEXTUAL E UNIVERSIDADES COMUNITÁRIAS}

Atualmente, o avanço rumo a uma sociedade assentada em valores de sustentabilidade, é muito lento. É necessário que se estabeleça um diálogo do campo acadêmico, do governo, do setor empresarial com a sociedade civil, a fim de avançar para o desenvolvimento sustentável (JACOBI, RAUFFLET E ARRUDA, 2011). Ou seja, existir um movimento de toda a humanidade para que a sustentabilidade aconteça.

As 11 universidades, quando questionadas sobre quem solicitou a inserção da temática nas universidades, seis responderam que foi a sociedade, quatro que foi o governo e um qur foram alunos e professores, conforme a gráfico 1 . 
Gráfico 1 Influências externas para a inserção da sustentabilidade

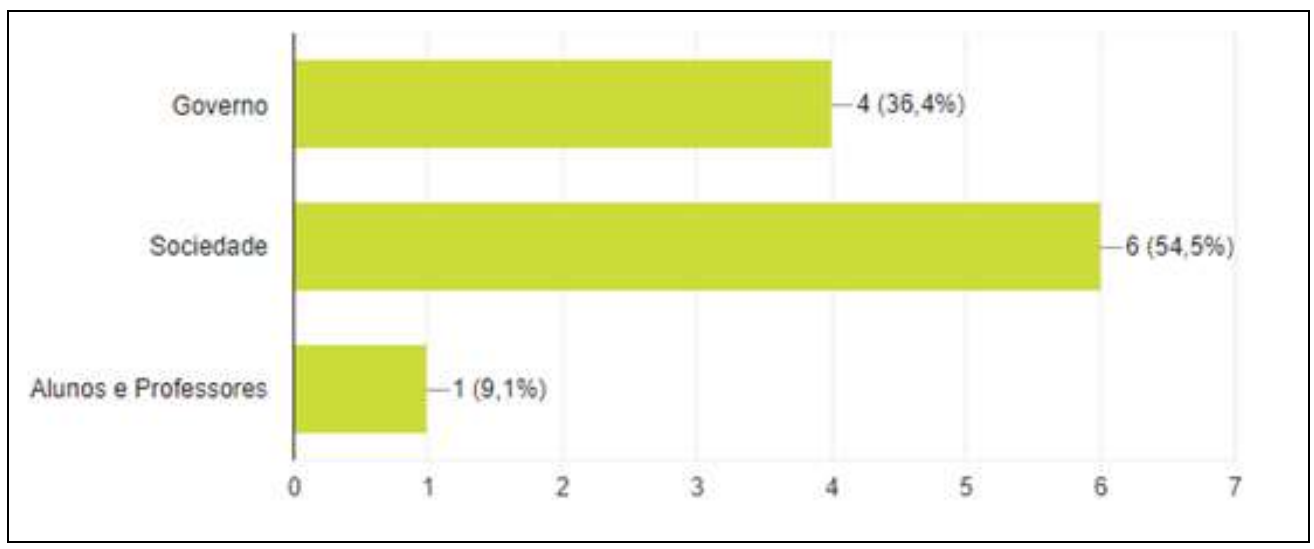

Fonte: dados da pesquisa.

$\mathrm{Na}$ perspectiva dos reitores entrevistados referentes a esse questionamento, ficou evidente, também, que a inserção da sustentabilidade nas universidades vem de vários atores, sejam eles a sociedade, o governo, alunos e professores, sem uma uniformidade de quem mais influenciou, ou seja, uma conscientização coletiva vem se desenvolvendo desde os primeiros sinais de que a sustentabilidade é necessária. Cabe ressaltar que todos evidenciaram um certo protagonismo das universidades comunitárias para inserir a sustentabilidade na sociedade, seja por projetos de extensão, seja por projetos de pesquisa, conforme evidenciado nas falas dos entrevistados a seguir.

Entrevistado A: quando iniciaram as movimentações em prol da sustentabilidade, a universidade já começou a estabeler iniciativas, o que fez ela se tornar, também, um agente protagonista da inserção do tema. Por exemplo, a universidade possui, desde 1998, o Instituto do Meio Ambiente, ou seja, são 20 anos atuando na inserção do tema por meio de projetos e isso é só um dos projetos da universidade, por exemplo.

Entrevistado D: é interessante deixar bem claro que, desde que se iniciou a universidade, ela já foi pensada pelo caráter da sustentabilidade, na época não tinha essa nomenclatura, pois a sustentabilidade em si é um termo novo e em desenvlvimento. Mas o que fez ela já se estruturar no caráter sustentável foi sua natureza comunitária, que tem muito disso.

Veiga et al (2012) resssaltam que as universidades comunitárias têm uma preocupação com o todo, e não somente com o ensino, que é o carater básico de uma universidade. Elas prestam serviços sociais gratuitos e de utilidade pública que podem ser caracterizados como: responsabilidade social, filantropia, voluntariado ou projetos de extensão, que embora estejam ligados às atividades sociais possuem particularidades e devem receber tratamento diferenciado. Nesse sentido, os respondentes, quando questionados sobre a influência da 
natureza comunitária na inserção da sustentabilidade, sete responderam que talvez (conforme Gráfico 2), uma vez que a natureza comunitária, em termos, pode ser comparada à sustentabilidade, pois busca inserir o maior número de dimensões existentes.

Gráfico 2 Natureza comunitária e a inserção da sustentabilidade

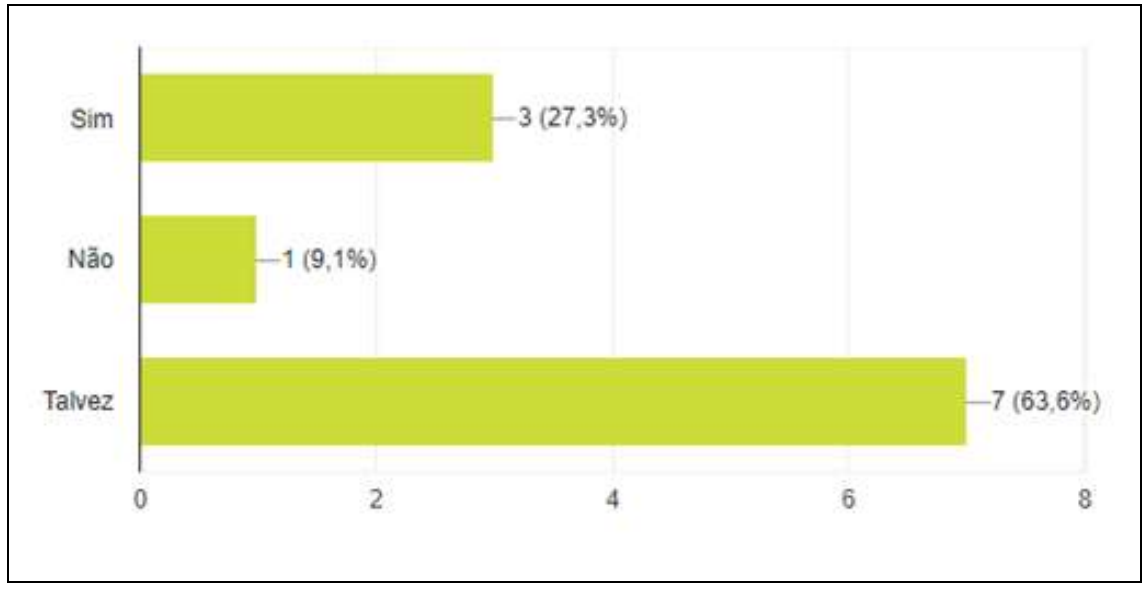

Fonte: dados da pesquisa.

Segundo os gestores, as diretrizes comunitárias estão alinhadas com a sustentabilidade, uma vez que as universidades comunitárias possuem forte vínculo com suas comunidades e com gestão democrática e participativa da sociedade da região que a universidade pertence. Evidencia-se isso nas seguintes falas dos entrevistados.

\subsection{DIMENSÃO ORGANIZACIONAL E UNIVERSIDADES COMUNITÁRIAS}

A sustentabilidade passou a ser tema abordado nas rotinas administrativas das instituições de ensino, desde as pequenas transações até os grandes investimentos (LOPES, SCHAFFER, BERTÉ, 2014). Nas universidades comunitárias não foi diferente, pois, conforme Gráfico 3, sete delas possuem rotinas administrativas que buscam seguir a sustentabilidade.

Nas entrevistas não foi diferente. Todos os gestores afirmaram que as rotinas administrativas seguem os preceitos da sustentabilidade. Cabe destacar, porém, que cada universidade está em uma etapa diferente quanto à tematica, conforme evidenciado nas manifestações dos entrevistados:

Entrevistado D: no início, houve uma formação continuada e um trabalho de conscientização dos nossos colaboradores, foi trabalhado muito forte. Atualmente, pode-se dizer que já faz parte da cultura da universidade seguir rotinas administrativas sustentáveis. Cabe destacar que a formação 
continuada não acontece mais, uma vez que, quando um novo colaborador ingressa, os demais colaboradores já repassam a forma com que trabalhamos aqui.

Entrevistado B: estamos com um trabalho de conscientização ainda. Como temos muitos colaboradores, fica mais dificil acessar a todos. Então, tomamos algumas atitudes genéricas ainda, como colocar lembretes em paredes, tomadas, lixeiras, e-mails exlicativos. Mas acredito que estamos no caminho certo.

Entrevistado A: antigamente, quando se falava em produto, se falava só de seus beneficios. Hoje, com a sustentabilidade não se vê a questão quanto à poluição somente, quanto ao cunho social e tudo mais. Nesse sentido, a universidade se adaptou também. Trouxe ao campus e às suas rotinas administrativas um novo olhar, de reuso, reciclagem, descarte correto, uso consciente e isso de duas décadas para cá, este cuidado foi aumentando.

Gráfico 3 Rotinas administrativas e a inserção da sustentabilidade

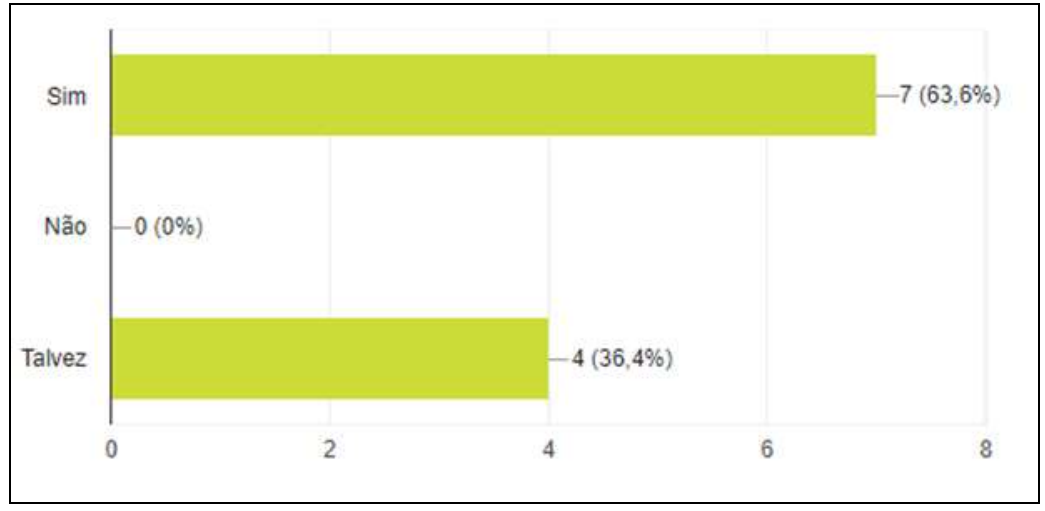

Fonte: dados da pesquisa.

A fala do entrevistado $\mathrm{D}$, já adianta a próxima questão: se existe a capacitação dos colaboradores dessas universidades em prol da temática. Conforme Gráfico 4, verifica-se que 6 universidades possuem essa capacitação. A Agenda 21 enfatiza que a educação é o meio para uma maior conscientização em relação à sustentabilidade. Logo, quando se fala em adequar as rotinas às questões ligadas à temática, é necessário que haja uma conscientização geral dos colaboradores.

Outro ponto a se destacar é que, nas entrevistas, os gestores foram questionados se existia algum índice de avaliação sobre sustentabilidade na instituição, seja na avaliação institucional interna, seja na avaliação do perfil do egresso. Todas as respostas foram negativas. Porém, todos comentaram que seria muito interessante criar este indicador. 
Gráfico 4 Capacitação de colaboradores para a sustentabilidade

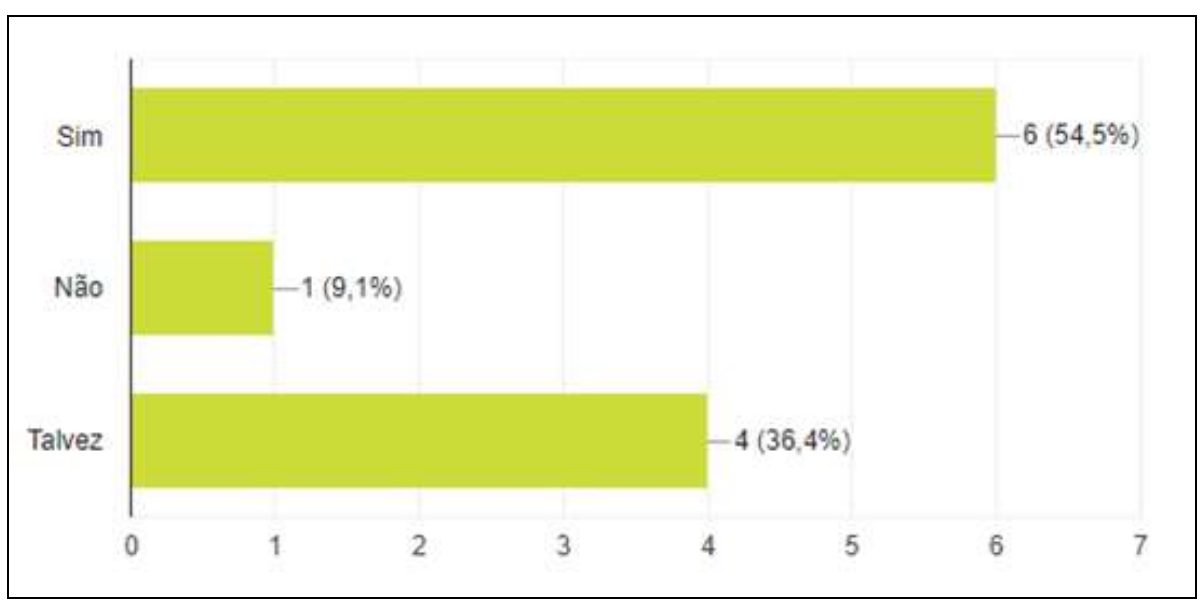

Fonte: dados da pesquisa.

\subsection{DIMENSÃO CURRICULAR E PEDAGÓGICA NAS UNIVERSIDADES COMUNITÁRIAS}

Barbieri e Silva (2011) apontam que não deve existir apenas uma disciplina isolada sobre a temática, e que ela deve ser introduzida em todas as oportunidades de ensino, como um processo contínuo, inclusive fora das instalações escolares, considerando o meio ambiente em suas múltiplas dimensões. Os gestores, quando perguntado se as universidades possuíam uma disciplina isolada, cinco afirmaram. Porém, quando questionado se a universidade busca integrar a sustentabilidade em todos os seus cursos, as respostas foram unânimes, de forma positiva, conforme evidenciado nos Gráficos 5.

Gráfico 5 Disciplina obrigatória sobre sustentabilidade

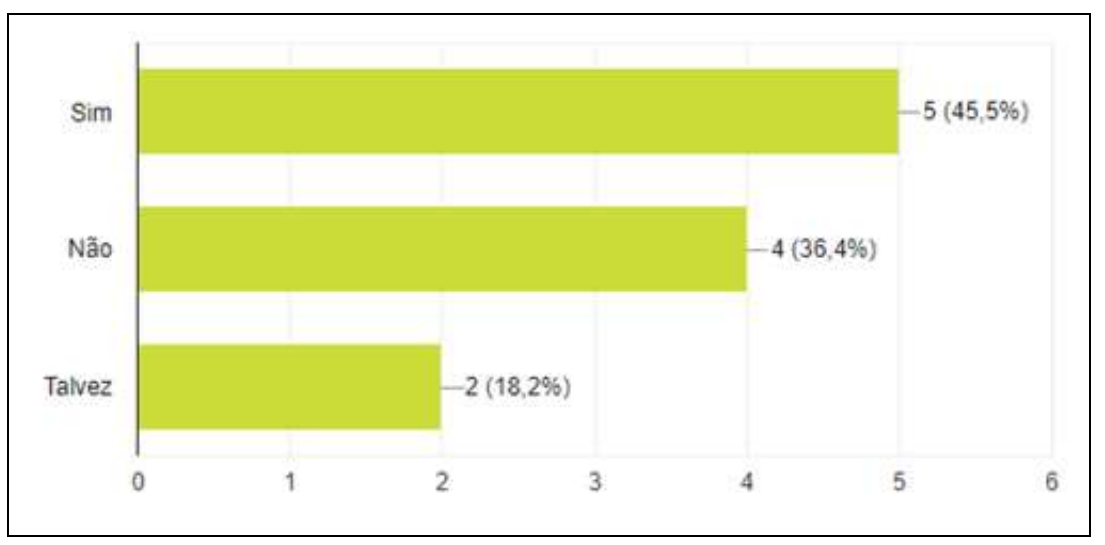

Fonte: Dados da pesquisa.

Os gestores, quando questionados sobre disciplinas obrigatórias ou não sobre a temática, afirmaram que a sustentabilidade é inserida em todos os cursos das universidades, 
entretanto que não existe uma disciplina obrigatória a todos os cursos. Destaca-se que eles comentaram cada curso é orientado a inserir ou a escolher uma disciplina que trabalhe com esse tema com mais evidência que as demais, devido às exigências legais e os critérios de avaliação do SINAES. O que ressalta-se nas seguintes falas dos entrevistados.

Entrevistado D: não temos uma disciplina comum a todos os cursos, mas orientamos desde a construção dos projetos político-pedagógicos que uma disciplina seja mais orientada à temática.

Entrevistado B: além dos cursos que têm disciplinas obrigatórias sobre a temática, engenharia ambiental, por exemplo, orientamos que haja pelo menos uma disciplina, nem que seja eletiva, sobre a temática. A maioria dos cursos cumpre essa orientação, o que tem trazido bons frutos para a universidade.

Entrevistado A: isso varia um pouco de curso para curso, até pela quantidade de cursos que temos. Até então, temos em torno de 60 disciplinas sobre a temática, mas não são disciplinas transversais a todos os cursos e sim adaptadas a cada curso. Mas buscamos inserir em todos os cursos sim.

Sibbel (2009), Armstrong (2011), Figueiró e Raufflet (2015), vêm apontando que, para que a EpS seja internalizada pelo aluno com sucesso, as preferências pedagógicas devem ser orientadas para uma epistemologia construtivista, caracterizados por altos níveis de envolvimento do aluno. Quando questionado aos gestores se as gestões fomentavam o uso dessas práticas, nove respondentes afirmaram que sim, utilizando mais a aprendizagem ativa, aprendizagem baseada em problemas e projetos, conforme Gráficos 6 e 7 .

Gráfico 6 Apoio da universidade a docentes.

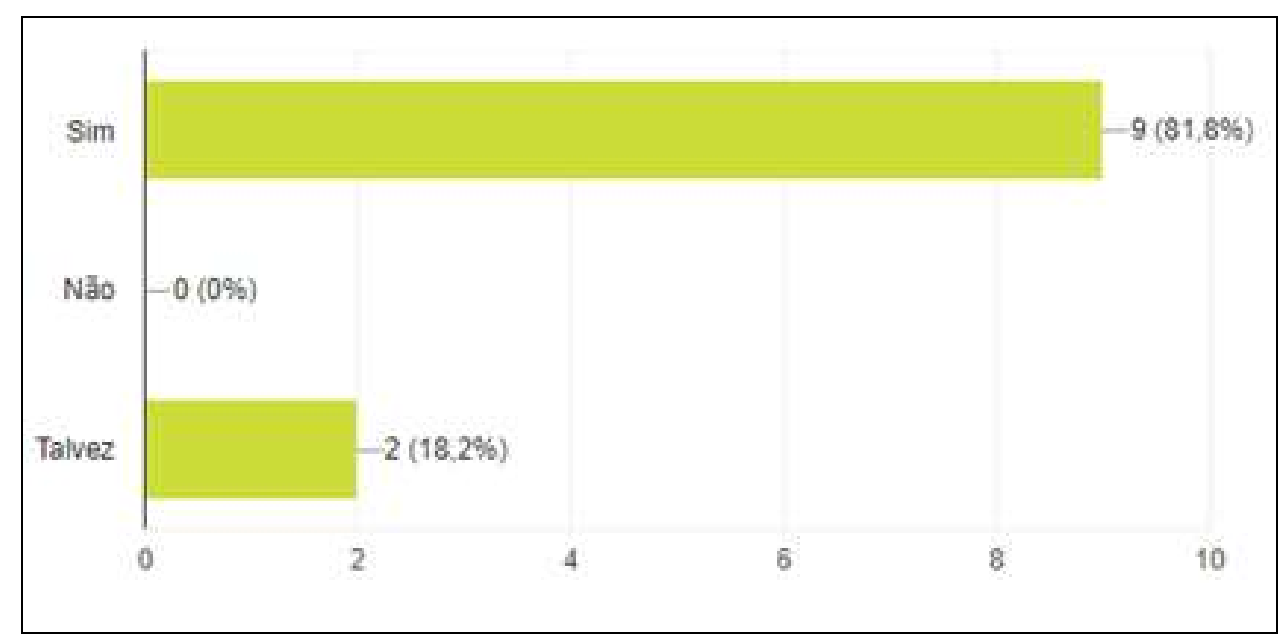

Fonte: Dados da pesquisa. 
Gráfico 7 Metodologias incentivadas

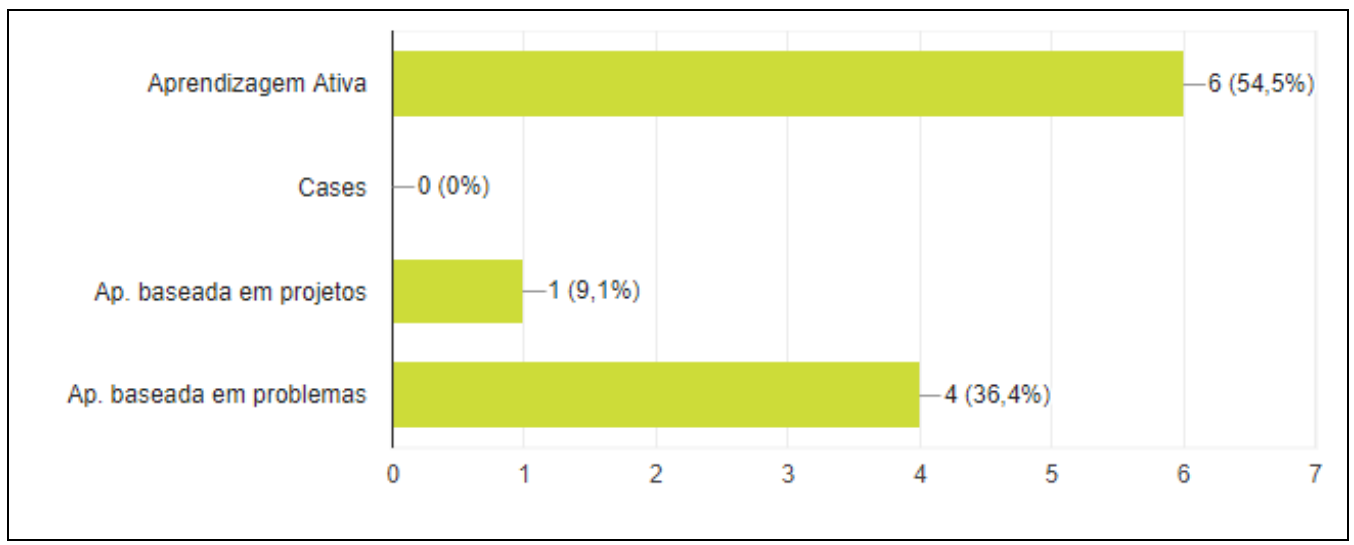

Fonte: Dados da pesquisa.

Foi unânime na fala dos entrevistados o fomento à utilização de metodologias ativas pelos seus professores, não só para a temática sustentabilidade, mas para todas as disciplinas existentes. Comentam ainda que é um amplo desafio para as universidades conscientizar seus professores a utilizarem essa metodologia. Barreiros (2008) afirma que é por meio da figura do professor que a aprendizagem acontece, e que ele precisa estar consciente de seu trabalho, pois exerce grande influência sobre o aluno. Mas e o papel da gestão? Barreiros (2008) conclui ainda que a gestão estratégica deve influenciar seus docentes, uma vez que todos são conscientes de seus papéis perante a EpS. Assim, o processo de integração é facilitado. Então foi questionado aos gestores se havia um direcionamento da gestão para a conscientização dos docentes, e mais de $60 \%$ disse que sim, conforme Gráfico 8:

Gráfico 8 Formação continuada sobre sustentabilidade.

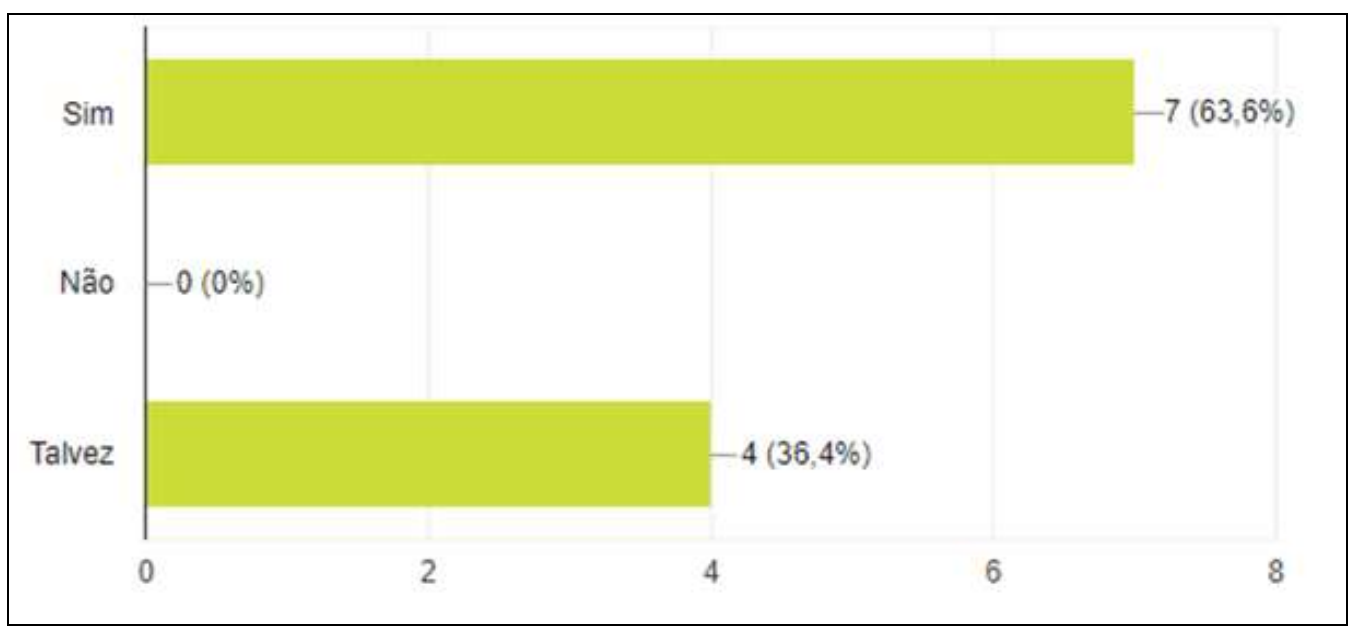

Fonte: Dados da pesquisa. 
A partir das manifestações dos gestores, não se obteve uniformidade de respostas. Algumas universidades não fornecem formação continuada sobre sustentabilidade, outras fomentam o uso da temática de outras formas e não uma ação de formação e outras buscam inserir seus professores na temática de forma contínua.

Percebe-se que todas as universidades buscam inserir a sustentabilidade em todo o seu ciclo, seja da parte administrativa e até nos cursos e disciplinas que oferecem. A UNESCO (1999) destaca que a capacitação para a atuação transdisciplinar é um dos pré-requisitos básicos para colocar em prática as noções de desenvolvimento sustentável, além de ser encarada como um compromisso da universidade na formação integral de seus alunos. Logo, quando questionadas sobre de que modo as universidades veem a sustentabilidade, cinco acreditam que ela é transversal. O restante acredita que a temática é interdisciplinar, multidisciplinar ou disciplina isolada, conforme Gráfico 9.

Gráfico 9 Visão da sustentabilidade nas universidades pesquisadas.

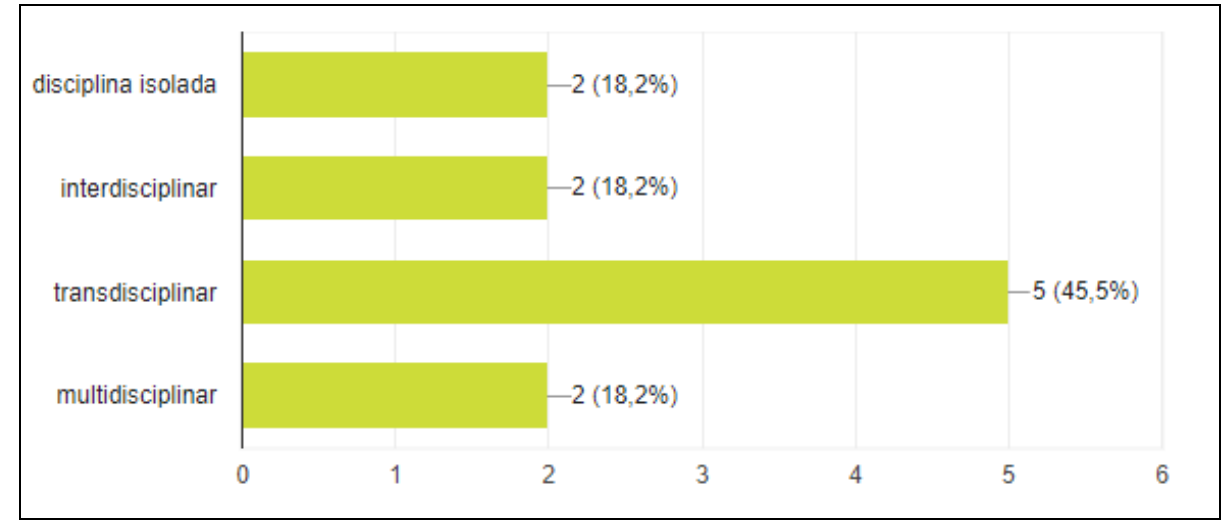

Fonte: Dados da pesquisa.

$\mathrm{Na}$ visão dos entrevistados, esses dados são reafirmados, ressaltando que as quatro universidades buscam inserir a sustentabilidade transversalmente. Outro ponto a se destacar é o protagonismo dessas gestões, no que se refere ao fomento para que a temática seja transdisciplinar. Por mais que existam disciplinas com a temática nos cursos, eles trabalham para que as demais disciplinas envolvam a temática, conforme destacado nas seguintes falas dos entrevistados.

Entrevistado A: por exemplo, o curso de Design tem uma disciplina que se chama laboratório, onde os alunos são desafiados a produzir produtos com cunho sustentável. Neste semestre, todas as demais disciplinas vão orbitar sobre a temática, a fim de melhor estimular o trabalho do aluno, unindo todos os conteúdos para seu produto. Ou seja, criando conexões. 
Entrevistado D: a sustentabilidade está tão difundida em nossa cultura que é natural a inserção da mesma nas mais diversas disciplinas, os coordenadores já sabem que têm que dar conta da temática em seus cursos e projetos político-pedagógicos.

Em um primeiro momento, foi questionado aos reitores se as universidades fomentavam projetos de pesquisa com recursos financeiros. Agora, foram questionados sobre os projetos de extensão: no questionário, se eles existiam; nas entrevistas, se percebiam o aumento desses projetos e como percebiam o fomento a isso. As onze instituições pesquisadas afirmam haver nas universidades projetos de extensão ligados à temática. O que reafirma o estudo de Barbieri e Silva (2011), que define que a sustentabilidade deve ser como um processo contínuo, fora das instalações escolares.

$\mathrm{Na}$ visão dos gestores, mais uma vez o caráter comunitário fica evidente quando relacionado com a sustentabilidade. Sem projetos de extensão, as universidades dariam pouco resultado para a sociedade e região que as cercam, conforme fica evidente nas seguintes falas dos gestores.

Entrevistado B: a universidade investe $3 \%$ em projetos de extensão e pesquisa, capital próprio, a indução desses recursos vai para cursos e áreas que mais precisamos de alavancagem e sustentabilidade é um exemplo disso.

Entrevistado C: olha, em nossos documentos está bem explícito que fomentamos projetos de extensão nas mais diversas áreas inclusive a sustentabilidade, mas estamos com certa dificuldade, nem sempre a prática coincide com os documentos, mas estamos procurando encaixar tudo.

Outros pontos a se destacar nas entrevistas é o crescente número de programas de pósgraduação que vêm iniciando na temática, o recurso que vem sendo investido para isso, o número de dissertações e teses que vem se desenvolvendo na temática e a consequência natural de desenvolvimento de grupos de pesquisa na área. Percebe-se isso nas seguintes falas dos entrevistados.

Entrevistado B: temos um curso de pós-graduação com avaliação 5, queremos que ele alcance a excelência, 6 e 7, então há um esforço institucional para que isso aconteça, então o pesquisador também se esforça para conseguir fomento para sua pesquisa.

Entrevistado D: fomentamos muito a pesquisa sobre a temática, se você for olhar nosso quadro de mestrados, praticamente todos tem um cunho sustentável, o que gera um ciclo, é mais pesquisa, mais projetos, mais grupos de pesquisa, mais fomento. A universidade é comprometida com a temática. 
Ademais, percebe-se que as dimensões se perpassam, principalmente quando se trata em retorno para a sociedade. Todo o esforço institucional pelo ensino, pesquisa e extensão vem se reforçando a cada dimensão, juntamente com o caráter comunitário das instituições.

Como já mencionado, Silva et al (2013) evidenciam que um indivíduo consciente faz uso do seu poder de reflexão frente às suas escolhas, podendo minimizar assim os impactos negativos destas. Logo, crê-se que as universidades são condinzentes com este discurso, e foram questionadas sobre isso conforme Gráfico 10.

Gráfico 10 Recursos financeiros e sustentabilidade

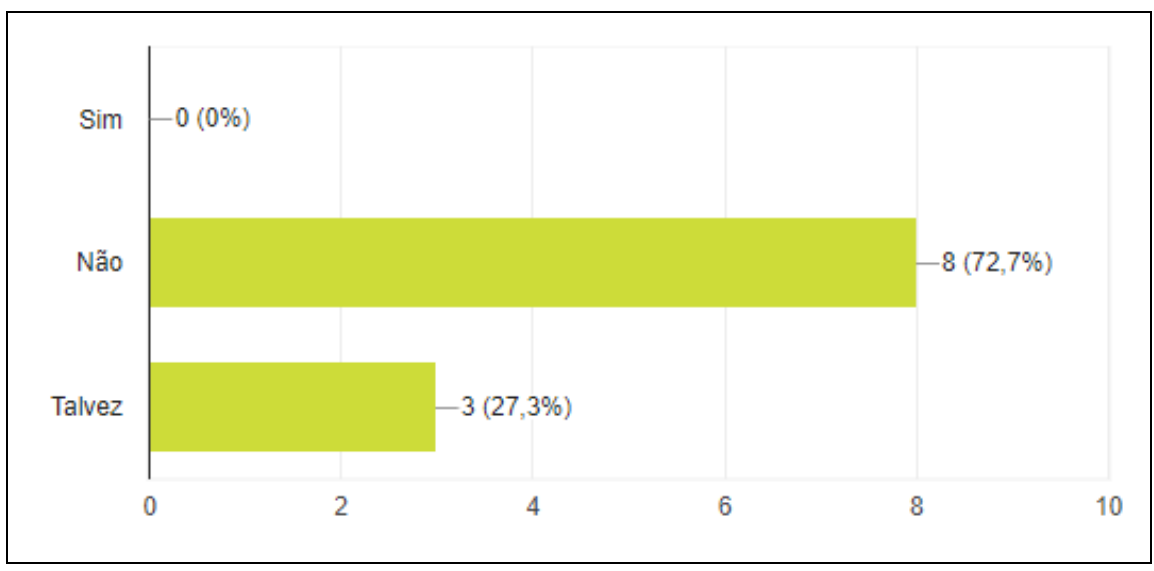

Fonte: Dados da pesquisa.

Oito respondentes afirmaram que não deixariam de receber recursos para um projeto que não coincidisse com as diretrizes da sustentabilidade, isso no questionário. Nas entrevistas, não houve nenhuma resposta específica. Apenas acreditam que não receberiam, conforme falas abaixo.

Entrevistado A: acredito que não, mas antes de concordarmos o projeto seria muito bem avaliado e, se víssemos que teria mais coisas negativas que positivas, não tem porque aceitar.

Entrevistado D: os projetos aqui passam pelo setor de fiscalização de projetos. Então, se tivesse coisas negativas, nem sairia dali.

Esse questionamento gerou certo desconforto nos entrevistados, que ainda ressaltaram o cuidado especial que as universidades comunitárias precisam tomar quanto a recursos, pois elas precisam deles, uma vez que suas fontes de renda são somente das mensalidades dos alunos, e para retornar seus ativos para a comunidade é necessário o lucro, uma vez que sem recursos financeiros a universidade poderá ter dificuldades para continuar existindo. 


\section{CONSIDERAÇÕES FINAIS}

A fim de melhor evidenciar os elementos que permitem a integração da sustentabilidade nas universidades comunitárias, por categorias. Na dimensão contextual é possível identificar como elementos que permitem a integração da temática sustentabilidade nas universidades comunitárias: a preocupação com o SINAES, o protagonismo dessas universidades introduzir a temática sustentabilidade para seu alunos e sociedade, o caráter comunitário (preocupação de dar retorno para a sociedade), e a preocupação entre a sustentabilidade financeira, ambiental e social.

$\mathrm{Na}$ dimensão organizacional a sustentabilidade insere-se for meio de elementos como: construção do PDI embasado na sustentabilidade, busca pela mudança cultural e inserção da temática em todos os departamentos das universidades, fomento a pesquisa sobre sustentabilidade, a preocupação dessas universidades de serem exemplos para a sociedade e formação continuada para colaboradores. $\mathrm{Na}$ dimensão curricular, destacam-se os seguintes elementos: busca por tranversalizar a sustentabilidade, fomento a interação com a comunidade com projetos de extensão sobre a temática sustentabilidade, incentivo a pesquisa e fomento de horas pesquisadas para docentes.

O fomento a utilização de metodologias ativas, busca por profissionais adeptos a sustentabilidade e formação docente sobre a temática destacam-se como elementos que permitem a integração da sustentabilidade em universidades comunitárias na dimensão pedagógica. Apresenta-se o Quadro 2, como síntese dos elementos que permitem a integração da sustentabilidade em universidades comunitárias.

Quadro 2 Elementos que permitem a integração da sustentabilidade

\begin{tabular}{|l|l|l|}
\hline \multirow{2}{*}{} & \multicolumn{1}{|c|}{ Categorias } & \multicolumn{1}{c|}{ Elementos que permitem a inserção da temática } \\
\cline { 2 - 3 } & Governo MEC & -certa preocupação com o SINAES, porém pouco citada. \\
\cline { 2 - 3 } & $\begin{array}{l}\text { Razões para a } \\
\text { inserção }\end{array}$ & $\begin{array}{l}\text { - iniciou pela sociedade, alunos, governo. } \\
\text { - protagonismos das universidades. }\end{array}$ \\
\cline { 2 - 3 } & Natureza da IES & $\begin{array}{l}\text {-caráter comunitário. } \\
\text {-preocupação das universidades comunitárias em dar retorno à } \\
\text { sociedade. }\end{array}$ \\
\cline { 2 - 3 } & $\begin{array}{l}\text { Capacidade do } \\
\text { curso }\end{array}$ & \begin{tabular}{l} 
- relação sustentabilidade financeira. \\
\cline { 2 - 3 }
\end{tabular} \\
\cline { 2 - 3 } & $\begin{array}{l}\text { Localização } \\
\text { geográfica }\end{array}$ & $\begin{array}{l}\text { Boa relação com a região da universidade. } \\
\text { - relação de ganha-ganha entre todos os envolvidos da região. }\end{array}$ \\
\hline
\end{tabular}




\section{EDUCAÇÃO PARA A SUSTENTABILIDADE NA GESTÃO ESTRATÉGICA DE UNIVERSIDADES \\ DOI: http://dx.doi.org/10.5007/1983-4535.2020v13n2p92}

\begin{tabular}{|c|c|c|}
\hline \multirow{6}{*}{ 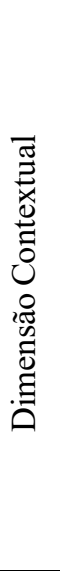 } & Categorias & Elementos que permitem a inserção da temática \\
\hline & Governo MEC & -certa preocupação com o SINAES, porém pouco citada. \\
\hline & $\begin{array}{l}\text { Razões para a } \\
\text { inserção }\end{array}$ & $\begin{array}{l}\text { - iniciou pela sociedade, alunos, governo. } \\
\text { - protagonismos das universidades. }\end{array}$ \\
\hline & Natureza da IES & $\begin{array}{l}\text {-caráter comunitário. } \\
\text {-preocupação das universidades comunitárias em dar retorno à } \\
\text { sociedade. }\end{array}$ \\
\hline & $\begin{array}{l}\text { Capacidade do } \\
\text { curso }\end{array}$ & - relação sustentabilidade financeira. \\
\hline & $\begin{array}{l}\text { Localização } \\
\text { geográfica }\end{array}$ & $\begin{array}{l}\text { Boa relação com a região da universidade. } \\
\text { - relação de ganha-ganha entre todos os envolvidos da região. }\end{array}$ \\
\hline \multirow{3}{*}{ 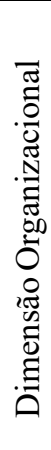 } & $\begin{array}{l}\text { Estrutura } \\
\text { organizacional }\end{array}$ & $\begin{array}{l}\text { - Temática presente no PDI da instituição. } \\
\text { - mudança cultural em desenvolvimento. } \\
\text { - Existência de ações por parte da gestão estratégica. } \\
\text { - crescente formação para os colaboradores. }\end{array}$ \\
\hline & $\begin{array}{l}\text { Desafios de } \\
\text { suporte }\end{array}$ & $\begin{array}{l}\text {-Fomento a pesquisas. } \\
\text {-preocupação das universidades em servirem de exemplo sobre a temática. }\end{array}$ \\
\hline & $\begin{array}{l}\text { Desafios } \\
\text { comportamentais }\end{array}$ & $\begin{array}{l}\text { - Adequação e aceitação dos colaboradores. } \\
\text { - Colaborador conscientizando colaborador. }\end{array}$ \\
\hline \multirow{4}{*}{ 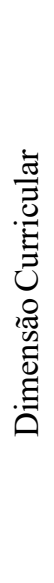 } & $\begin{array}{l}\text { Natureza da } \\
\text { disciplina }\end{array}$ & - trandisciplinar. \\
\hline & $\begin{array}{l}\text { Presença no } \\
\text { currículo }\end{array}$ & $\begin{array}{l}\text { Sustentabilidade inserida em todos os cursos. } \\
\text { Presença do tema especificamente é maior na pós- graduação do que na } \\
\text { graduação; } \\
\text { Na graduação busca-se inserir transversalmente, não dando enfoque } \\
\text { principal como na pós-graduação. }\end{array}$ \\
\hline & Extensão & $\begin{array}{l}\text { - Extensão vista como lugar onde se entrega a comunidade o } \\
\text { investimento feito; } \\
\text { - Fomento a interação com a comunidade. } \\
\text { - Tentativa de inserir professores de todas as áreas em projetos sobre a } \\
\text { temática. }\end{array}$ \\
\hline & Pesquisa & $\begin{array}{l}\text { Fomento a pesquisas na área em crescimento. } \\
\text { Incentivo de horas para docentes realizarem pesquisas na área. }\end{array}$ \\
\hline \multirow{3}{*}{ 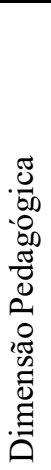 } & $\begin{array}{l}\text { Estratégia em } \\
\text { sala de aula }\end{array}$ & - Fomento a utilização de metodologias ativas, em todas as áreas. \\
\hline & $\begin{array}{l}\text { Orientação de } \\
\text { TCC }\end{array}$ & - Fomento a estudos, como PIBICs \\
\hline & $\begin{array}{l}\text { Formação do } \\
\text { professor }\end{array}$ & $\begin{array}{l}\text { Busca por docentes já adeptos a temática. } \\
\text { Formação para todos os docentes na temática. } \\
\text { Fomento a inserção do tema. }\end{array}$ \\
\hline
\end{tabular}

Fonte: Dados da pesquisa. 


\section{EDUCAÇÃO PARA A SUSTENTABILIDADE NA GESTÃO ESTRATÉGICA DE UNIVERSIDADES

A partir dos resultados encontrados foi possível ter um panorama da sustentabilidade nas universidades comunitárias. Foi possível também apresentar possíveis avanços na integração da temática. $\mathrm{Na}$ dimensão contextual, pode-se desenvolver um índice de sustentabilidade interno (pesquisa com professores, alunos e colaboradores) a fim de facilitar e melhor atender o SINAES, ampliar as parcerias entre as universidades comunitárias a fim de construir eventos e ações em conjunto, assim compilando gastos e diminuindo onerações, e também estreitar laços com stakeholders a fim de otimizar ações em prol da sociedade.

Por sua vez, a dimensão organizacional pode avançar em além de manter as formações continuadas para seus colaboradores, desenvolver gincanas sustentáveis a fim de ter maior engajamento em prol da temática (visto que a sustentabilidade de na pratica é mais facilmente internalizada) e aperfeiçoar os espaços das universidades, como espaços de coworking por exemplo. Na dimensão curricular vê-se avanços no sentido de unir as ICES nos projetos de extensão, assim atingindo um maior número da população, ampliar relações entre pesquisa sobre a temáticas entre cursos de graduação e pós-graduação e maior fomento a transversalização da sustentabilidade, como por exemplo, rodas de conversa entre cursos e ou disciplinas.

Fomento a utilização de metodologias ativas, desenvolvimento do índice de sustentabilidade em disciplinas e maior número de pesquisas sobre a temática, percebem-se como possíveis avanços na dimensão pedagógica. Abaixo, apresenta-se possibilidade de avanços para a integração da temática conforme Quadro 3, embasado na literatura e estudos citados no capítulo da revisão teórico-conceitual.

Percebe-se que as universidades comunitárias tem ampla preocupação com a temática sustentabilidade, buscam estar atualizados em relação ao tema e repassar a seus alunos por meio de projetos de pesquisa e extensão e no ensino. Porém, uma vez que a sociedade está em pleno desenvolvimento, e os recursos são limitados, e essas mesmas universidades tendem a continuar o desenvolvimento da temática sustentabilidade, a fim de acompanhar e corroborar barra o desenvolvimento sustentável da sociedade.

Como limitações a este estudo, pode-se apontar a abrangência do mesmo, assim não obtendo uma profundidade relevante, a dificuldade de contatar de reitores das universidades e o tempo de pesquisa, uma vez que foi levado em consideração para a realização das entrevistas. São necessários estudos futuros para explorar a sustentabilidade em todas as universidades comunitárias individualmente, nas dimensões curricular e pedagógica, realizar 


\section{EDUCAÇÃO PARA A SUSTENTABILIDADE NA GESTÃO ESTRATÉGICA DE UNIVERSIDADES \\ COMUNITÁRIAS \\ DOI: http://dx.doi.org/10.5007/1983-4535.2020v13n2p92}

um estudo de caso com maior profundidade, a fim de detalhar as funções da gestão quanto a temática, replicar o estudo em universidades públicas e realizar uma futura comparação entre estas modalidades de universidades.

Quadro 3 Possíveis avanços na integração da temática

\begin{tabular}{|c|c|c|}
\hline \multirow{6}{*}{ 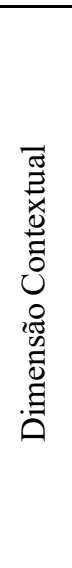 } & Categorias & Possíveis avanços \\
\hline & Governo MEC & - Índice de avaliação de sustentabilidade \\
\hline & $\begin{array}{l}\text { Razões para a } \\
\text { inserção }\end{array}$ & -ações em conjunto em prol da temática. \\
\hline & Natureza da IES & -maior união das ICES. \\
\hline & $\begin{array}{l}\text { Capacidade do } \\
\text { curso }\end{array}$ & $\begin{array}{l}\text {-união de cursos de diferentes instituições a fim de diminuir custos, mas } \\
\text { attender a sociedade. }\end{array}$ \\
\hline & $\begin{array}{l}\text { Localização } \\
\text { geográfica }\end{array}$ & -Aumento de parceria com stakeholders. \\
\hline \multirow{3}{*}{ 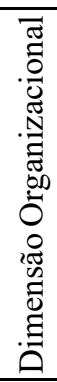 } & $\begin{array}{l}\text { Estrutura } \\
\text { organizacional }\end{array}$ & $\begin{array}{l}\text { - formação continuada sobre a temática. } \\
\text { - desenvolvimento de gincanas sustentáveis entre setores. }\end{array}$ \\
\hline & $\begin{array}{l}\text { Desafios de } \\
\text { suporte }\end{array}$ & $\begin{array}{l}\text { - otimizar espaços das universidades. } \\
\text { - união de ICES para atividades como TV's e rádios universitárias. }\end{array}$ \\
\hline & $\begin{array}{l}\text { Desafios } \\
\text { comportamentais }\end{array}$ & - Conscientização pelo exemplo. \\
\hline \multirow{4}{*}{ 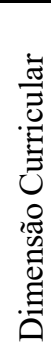 } & $\begin{array}{l}\text { Natureza da } \\
\text { disciplina }\end{array}$ & - maior fomento a trandisciplinariedade. \\
\hline & $\begin{array}{l}\text { Presença no } \\
\text { currículo }\end{array}$ & $\begin{array}{l}\text { Inserção dos cursos de pós-graduação e cursos de graduação, por meio de } \\
\text { palestras e eventos sobre a temática. } \\
\text { Compartilhamento de conhecimento. }\end{array}$ \\
\hline & Extensão & - Projetos de extensão unindo todas as ICES. \\
\hline & Pesquisa & Sinergia entre pós-graduação e cursos de graduação. \\
\hline & $\begin{array}{l}\text { Estratégia em } \\
\text { sala de aula }\end{array}$ & - Fomento a utilização de metodologias ativas. \\
\hline & $\begin{array}{l}\text { Orientação de } \\
\text { TCC }\end{array}$ & - Fomento a pesquisas na temática. \\
\hline & $\begin{array}{l}\text { Formação do } \\
\text { professor }\end{array}$ & $\begin{array}{l}\text { Formação continuada sobre a temática. } \\
\text { Índice de avaliação quanto a sustentabilidade em disciplinas. }\end{array}$ \\
\hline
\end{tabular}

Fonte: Dados da pesquisa.

Por fim, a educação é um processo de construção entre teoria e prática, ela é agente ativo de conscientização, de formar mentes que estejam em condições de criticar. Para isso, o 
conceito de educação para a sustentabilidade vem sendo explorado, desenvolver pessoas capazes de tomar decisões certas e preservar o mundo, com o real desenvolvimento sustentável. Pois a sustentabilidade, a vida e a universidade comunitária são como ciclos, e ajustando todas as partes desses ciclos é possível que o desenvolvimento sustentável aconteça.

\section{REFERÊNCIAS}

ARMSTRONG, C. M. Implementing Education for Sustainable Development: The Potential use of Time-Honored Pedagogical Practice from the Progressive Era of Education. Journal of Sustainability Education. v.2, mar, 2011.

BARBIERI, J. C. Desenvolvimento e meio ambiente. 7. ed. Petrópolis: Vozes, 2002.

BARBIERI, J. C. e SILVA D. Desenvolvimento sustentável e educação ambiental: uma trajetória comum com muitos desafios. Revista Adm. Mackenzie, V. 12, N. 3, mai/jun.2011.

BARBIERI, J. C. Educação ambiental e a gestão ambiental em cursos de graduação em Administração: objetivos, desafios e propostas. Revista de Administração Pública, 38(6), p. 919-946, 2004.

BARDIN, L. Análise de conteúdo. São Paulo: Edições 70, 2011.

CALGARO, C. Desenvolvimento sustentável: Uma realidade a ser alcançada. Revista Âmbito Jurídico. 2016. Disponível em $<$ http://www.ambitojuridico.com.br/site/index.php?n_link=revista_artigos_leitura\&artigo_id=534> Acesso em julho de 2016.

DEMAJOROVIC, J, SILVA, HCO da. Formação interdisciplinar e sustentabilidade em cursos de administração: desafios e perspectivas. Revista de Administração Mackenzie. Volume 13. Edição 5. Páginas 39. Editora Mackenzie Presbyterian University, 2012.

FIGUEIRÓ, P. S. Educação para a Sustentabilidade em cursos de graduação em Administração: Proposta de uma estrutura analítica. Tese de doutorado. Programa de Pós-Graduação em Administração da Universidade Federal do Rio Grande do Sul, Porto Alegre, 2015.

FIGUEIRÓ. Paola S.; RAUFFLET, Emmanuel. Sustainability in Higher Education: a systematic review with focus on management education. Journal of Cleaner Production, 2015 [In Press].

GIL, Antonio Carlos. Métodos e Técnicas de Pesquisa Social. 5 ed. São Paulo: Atlas, 1999.

HAFSI, Taïeb; MARTINET, Alain-Charles. Estratégia e gestão estratégica das empresas: um olhar histórico e crítico. Rev. Adm. Contemp. [online]. 2008, vol.12, n.4.

HESSELINK, F.; VAN KEMPEN, P.P.; WALS, A. ESDebate. International debate on education for sustainable development. Gland: IUCN, 2000.

JACOBI, P. R. Educação ambiental: o desafio da construção de um pensamento crítico, complexo e reflexivo. Educ. Pesqui. [online]. vol.31, n.2, pp. 233-250, 2005. 
JACOBI, P. R.; RAUFFLET, E; ARRUDA, M. P Educação para a sustentabilidade nos cursos de Administração: reflexão sobre paradigmas e práticas RAM, Rev. Adm. Mackenzie (Online) vol.12 no.3 São Paulo June 2011.

KURUCZ, Elizabeth C.; COLBERT, Barry A.; MARCUS Joel. Sustainability as a provocationto rethink management education: Building a progressive educative practice. Management Learning, Sage, 2013.

LAUDER, H., P. BROWN, J. A. DILLABOUGH \& A. H. Halsey. Education, globalization and social change. Oxford University Press, Oxford, 2006.

LAKATOS, E. M. MARCONI, M. A. Fundamentos de metodologia científica. $6^{\circ}$ ed. - São

LEITE, Y.; MORAES, W.; SALAZAR, V. O Processo De Internacionalização: UmaAnálise Qualitativa De Duas Exportadoras Do Nordeste. RACEF - Revista deAdministração,

Contabilidade e Economia da Fundace. v. 6, n. 2, p. 27-46, 2015.

LOPES, Fabiana Crivano, SCHAFFER, Rosely, BERTÉ, Rodrigo.

MARQUES, C. S. Educação para a Sustentabilidade: contribuições para o desenvolvimento do tema em Pós-Graduações em Administração. Dissertação de Mestrado. Programa de Pós-Graduação em Administração da Universidade Federal de Santa Maria, Santa Maria, 2016.

MEYER JR., V. Planejamento universitário:ato racional, político ou simbólico:um estudo de uni-versidades brasileiras. Revista Alcance,v. 12, n. 3, p. 373-389, set./dez. 2005

MEYER JR., V; Pascucci, L. e Mangolin, L. Gestão estratégica: um exame de práticas em universidades privadas. Red de Revistas Científicas de América Latina y el Caribe, España y Portugal. 2012.

MORAES, Roque. Análise de conteúdo. Revista Educação, Porto Alegre, v. 22, n. 37, p. 732, 1999.

STAKE, R. Case studies. In: DENZIN, N.; LINCOLN, Y. (eds.). Strategies of Qualitative Inquiry. Thousand Oaks, London, New Delhi: Sage, 1998.

STRAUSS, A.; CORBIN, J. Basics of Qualitative Research: Grounded theory procedures and techniques. Newbury Park, CA: Sage, 1990

TILBURY, D.; WORTMAN, D. Engaging people in sustainability. Gland, Switzerland: ICN, 2004.Acesso em fev. 2017.

Education for sustainability in further and higher education: reflections along the journey. Planning for Higher Education, Ann Arbour, v. 36, n. 4, p. 5-16, July/Sept. 2008. THOMAS, I.; HEGARTY, K.; HOLDSWORTH, S. The Education for Sustainability JigSaw Puzzle: Implementation in Universities. Creative Education, v.3, special issue, p.840846, 2012.

VEIGA, Luciane da; Drehmer, Clarice Luiza; Urnau, Jeferson Rafael; Silva, Talita da; Lizote, Suzete Antonieta; Terres, José Carlos. O QUE É UMA UNIVERSIDADE COMUNITÁRIA? Um estudo sobre o grau de conhecimento dos estudantes de uma Instituição de Ensino Superior. XII Colóquio Internacional sobre Gestão Universitária nas Américas, 2012. 